\title{
Modeling and Analysis of Milling Machine Control Process without/with Using Fuzzy Interface Mamdani Style Based On Matlab/Simulink
}

\author{
Bashir Osman ${ }^{1 *}$ and Haitao $\mathrm{Zhu}^{2}$ \\ ${ }^{1}$ College of Mechanical and Electrical Engineering, Harbin Engineering \\ University, No.145 Nantong Street, Harbin 150001.China \\ ${ }^{2}$ College of Mechanical and Electrical Engineering, Harbin Engineering \\ University, No.145 Nantong Street, Harbin 150001.China \\ ${ }^{1}$ Nile Valley University, Faculty of Engineering and Technology, Department of \\ Mechanical Engineering, P. O. Box 26, Atbara, Sudan \\ 'basheer931@hotmail.com, ${ }^{2}$ zhuhaitao@hrbeu.edu.cn
}

\begin{abstract}
Because of time-varying, nonlinearity and complexity of machining process, the traditional PID control has been unable to meet the requirements. However fuzzy control can be a good solution for this kind of control system. This article aims to establish a milling control process model according to the logic of cutting process mathematical terms with a servo system and give it appropriate processing parameters selected form reading references. The final model will be represent by using Simulink blocks. To insure the model is correct and comparable, the Matlab code will test the step response under various parameters, then fuzzy interface Mamdani type method will be added to the previous established model. This model will give us good opportunity to discuss the advantage and disadvantage of fuzzy control method different types, this work will focus to add and discuss one method.
\end{abstract}

Keywords: Control model; milling machining; Matlab/Simulink; Fuzzy controller

\section{Introduction}

There is [1] a variety of reasons for the installation of a monitoring system in a manufacturing process. Modern manufacturing equipment has to be flexible, sustainable and operative with minimum human interface, while machine tools have to operate free of errors. Two major problems in the field of metal cutting are tool wear and tool breakage. Number of schemes, techniques and paradigms have been used for the development of functional decision making systems that would derive a conclusion on machining process conditions, based on sensor signals [2-4]. The cognitive paradigms most frequently employed for the purpose of monitoring in machining, are the Neural Networks (NN) and Fuzzy Logic (FL).With the rapid development of fuzzy technologies, a lot of research has been done, different fuzzy control strategies have developed based on different methods, such as PID-fuzzy control [5], sliding - mode fuzzy control [6], neural fuzzy control, adapter fuzzy control and phase-plane mapping method fuzzy control [7].Fuzzy inference is the process of formulating the mapping from a given input to an output using FL. There are two types of fuzzy inference systems namely that are Mamdani-type and Sugeno-type [8].Mamdani method was among the first control systems built using fuzzy set theory. It was proposed in 1975 [9 and 10] as an attempt to control a steam engine and boiler combination. Mamdani style inference expects the output membership functions to be fuzzy sets. Mamdani style inference expects the output membership functions to be fuzzy sets. After the aggregation process, there is a fuzzy set for each output variable that needs 
defuzzification. It is possible, and in many cases much more efficient, to use a single spike as the output membership functions rather than a distributed fuzzy set. It enhances the efficiency of the defuzzification process because it greatly simplifies the computation required to find the centroid of a two-dimensional shape. In this paper, a milling process will be created in easy way, using the mathematical logic of milling machining process to do the analysis.

\section{Machining Process Control Model}

There are various numbers of modeling methods to predict the machining process from the cutting force effects point of view, such as FEM modeling, modeling geometric Raito of the engagement of the cutting tool [11-13]. Before we can control a system we must understand in mathematical terms how the system behaves without control [14]. Milling is one of the most well-known material removal techniques, where material is removed from work piece using rotating cutter [15]. According to the cutting logic, let us establish the model as following:

\subsection{Machining Process Control Model}

The process includes feed rate and cutting forces model.

2.1.1. Machining process model: Feed rate $f(\mathrm{~mm} / \mathrm{min})$ a milling-tool moves through the material being cut, this calculated using the feed per tooth $f_{z}(\mathrm{~mm} / \mathrm{teeth}), N$ (tooth) is the number of cutting teeth on the tool, and $n$ represents the angular velocity of the spindle (rev/min), The calculation of this formula will be:

$$
f=n \times f_{z} \times N
$$

Let us change the feed rate units form $(\mathrm{mm} / \mathrm{min})$ to $(\mathrm{mm} / \mathrm{sec})$

$$
f=n \times f_{z} \times N / 60
$$

\subsubsection{Cutting Forces Model}

It is well known that cutting forces are directly proportional to the chip area behavior [16-18]. A simplified orthogonal cutting force has been introduced in [12] to model the dynamics of the forces in the cutting process. The cutting forces $F_{c}$ that are expressed in Formula (3) composed of the specific cutting force $K_{C}\left(\mathrm{~N} / \mathrm{mm}^{2}\right)$, axial cutting depth $a_{p}(\mathrm{~mm})$ and the feed rate $f(\mathrm{~mm} / \mathrm{min})$ indexed to the exponent of the specific $\mathrm{m}$.

$$
F_{c}=K_{c} \times a_{p} \times f_{z}^{m}=\left(K_{c} \times a_{p} \times f_{z}^{m-1}\right) f_{z}
$$

The actual cutting force $F$ which is orthogonal and proportional to the tangential force can be described by following formula:

$$
F=K_{e} \times F_{c}
$$

Where, $K_{e}$ is the actual specific cutting force gain.

\subsection{The Servo System Model}

The basic form of a DC servo system is made by an electronic motor with an output shaft that has an inertial load $\mathbf{J}$ on it, and friction in the bearings of the motor and load (represent by the constant $b$ ), there will be an electrical drive circuit where input voltage $u$ (t) is transforming the motor into a torque $T(t)$ in the motor output shaft [14]. Using system modelling ideas for mechanical systems a torque balance can be written between the input torque from the motor and the torque required to accelerate the load overcome friction.

$$
J \ddot{\theta}+b \dot{\theta}=T(\mathrm{t})
$$


Where $\theta$ is the angular position of the servo output shaft, the control objective is control the shaft position $\theta$ or the shaft velocity $\theta^{\circ}$ to be some desire value. The input voltage $u(t)$ is related to the torque $T(t)$ by the gain $K_{n}$ and the inertia divided by the friction coefficient is referred to the as the system time constant $\tau$, where, $\tau=\mathrm{J} / \mathrm{b}$, so the system model becomes:

$$
\tau \ddot{\theta}+\dot{\theta}=K_{n} u(t)
$$

The standard form of the transfer function of a second -order system is:

$$
G(s)=\frac{Y(s)}{U(s)}=\frac{K_{n} \omega_{n}^{2}}{s^{2}+2 \zeta \omega_{n}+\omega_{n}^{2}}
$$

Where $Y(s)$ and $U(s)$ are the Laplace transforms of the output and input variables, respectively, $\omega_{n}$ is natural frequency, and $\zeta$ is damping ratio. According to the mechanism of the milling model system, input and output of the servo will be as a fellow:

$$
G(s)=\frac{f_{z}(s)}{u(s)}=\frac{K_{n} \omega_{n}^{2}}{s^{2}+2 \zeta \omega_{n}+\omega_{n}^{2}}
$$

\section{Machining Control Model Transfer Function Blocks}

According to formula (2), (3), (4) and (8), we can establish the model as shown in Figure 1.

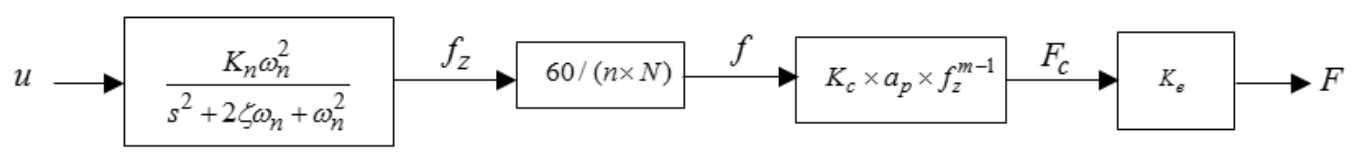

Figure 1. The Block Diagram of the System

The DC gain of the programmed system is :

$$
K=\frac{60 \times K_{n} K_{c} K_{e} a_{p} f_{z}^{m-1}}{n \times N}
$$

\section{Machining Control Model System Simulation}

In the present work, Matlab and Matlab/Simulink model has been developed to generate the model's transfer function to test the step response under various parameters. The simulation parameters are shown in Table 1.

Table 1. Input Simulation Parameters

\begin{tabular}{|c|c|c|c|}
\hline Parameter & Sample & Value & Unit \\
\hline Spindle speed & $n$ & 600 & $\mathrm{rev} / \mathrm{min}$ \\
\hline Servo gain & $k_{n}$ & 1 & $\mathrm{~mm} /(\mathrm{V} . \mathrm{s})$ \\
\hline Specific cutting force & $K_{c}$ & 1760 & $\mathrm{~N} / \mathrm{mm}^{2}$ \\
\hline Axial cutting depth & $\mathrm{a}_{\mathrm{p}}$ & 2 & $\mathrm{~mm}$ \\
\hline Damping ratio (zeta) & $\zeta$ & 0.5 & \\
\hline Number of teeth & $\mathrm{N}$ & 4 & teeth \\
\hline Natural frequency & $\omega_{n}$ & 20 & $\mathrm{rad} / \mathrm{sec}$ \\
\hline Exponent of the specific & $m$ & 0.7 & \\
\hline Specific actual cutting force & $K_{e}$ & 2 & $\mathrm{~N} / \mathrm{mm}^{2}$ \\
\hline
\end{tabular}




\subsection{The Matlab Simulation}

Matlab software able to create a continuous time transfer function with numerator and denominator specified by num and den. Step response is dynamic response of the system (assuming zero initial conditions) when the input is step function $u(t)=1, \mathrm{t} \geq 0$. In order to obtain the step response of the system, the command step is use with it is variations. According to Table 1 parameters Matlab code used to find out the impact of the exponent of the specific $m$, damping ratio $\zeta$ and natural frequency $\omega_{n}$ as:

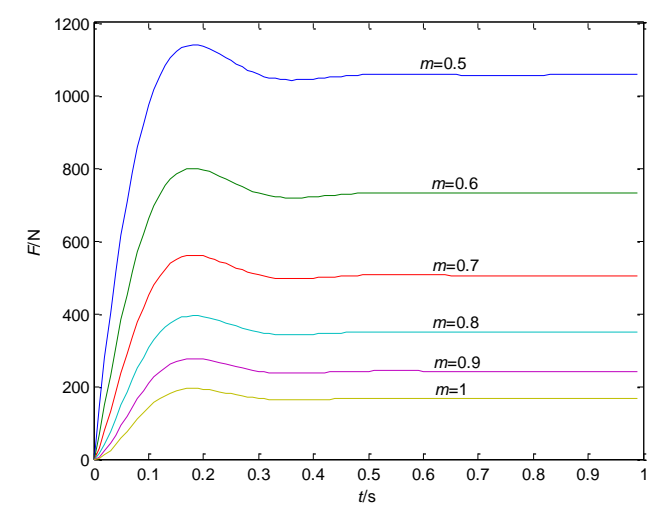

Figure 2. The Impact of Exponent of the Specific $m$

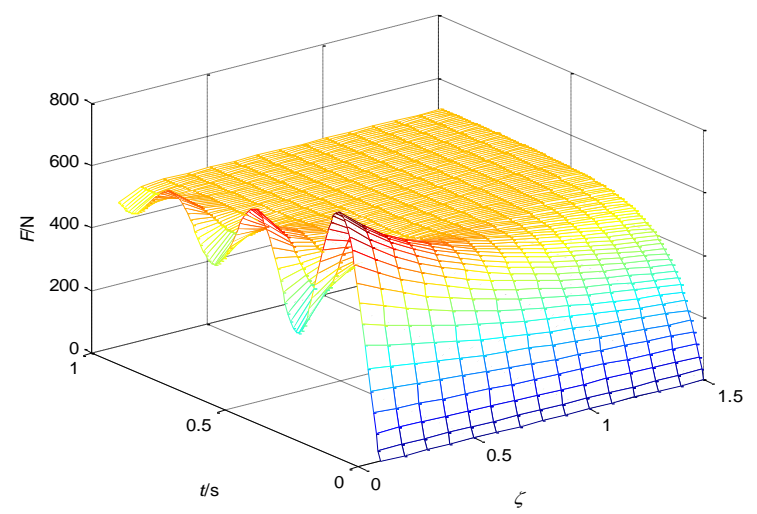

Figure 3. The Effect of Damping Ratio $\zeta$
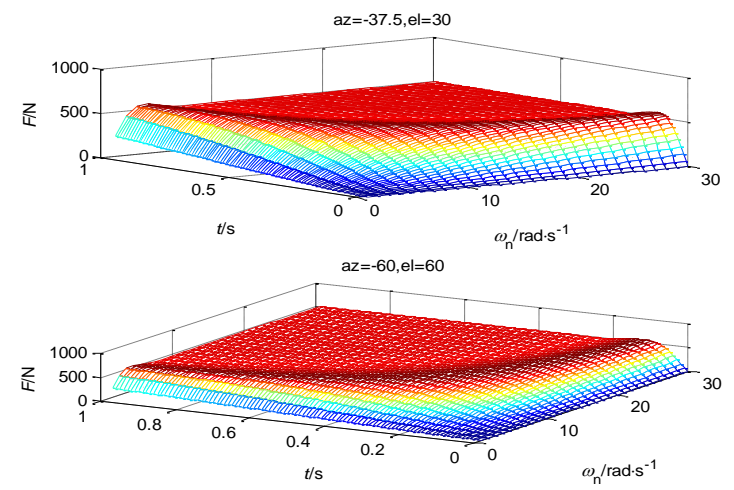

Figure 4. The Effect of Natural Frequency $\omega_{n}$ 


\subsection{Simulink Model}

All equation symbols must be defined in a clear and understandable way. Simulink developed by the Math Works, is a commercial tool for modeling, simulating and analyzing dynamic systems, and it's widely used in control theory. In the present work, Simulink model has been developed to generate the model. The Simulink toolbox is used to simulate the orthogonal milling control process considering the dynamic equation developed in the previous section. The Simulink simulation model shown in Figure 5.

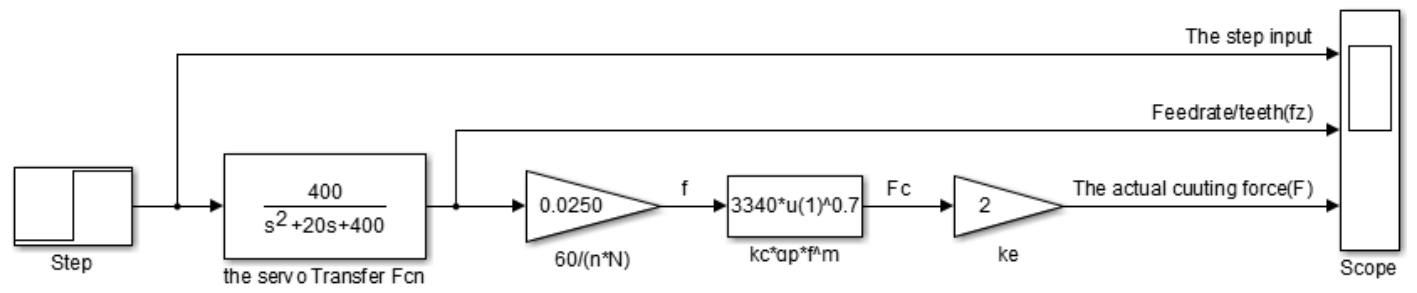

Figure 5. Simulink Model

The simulation parameters mentioned in Table 1, where the cutting process is active at $\mathrm{t}=5 \mathrm{sec}$.

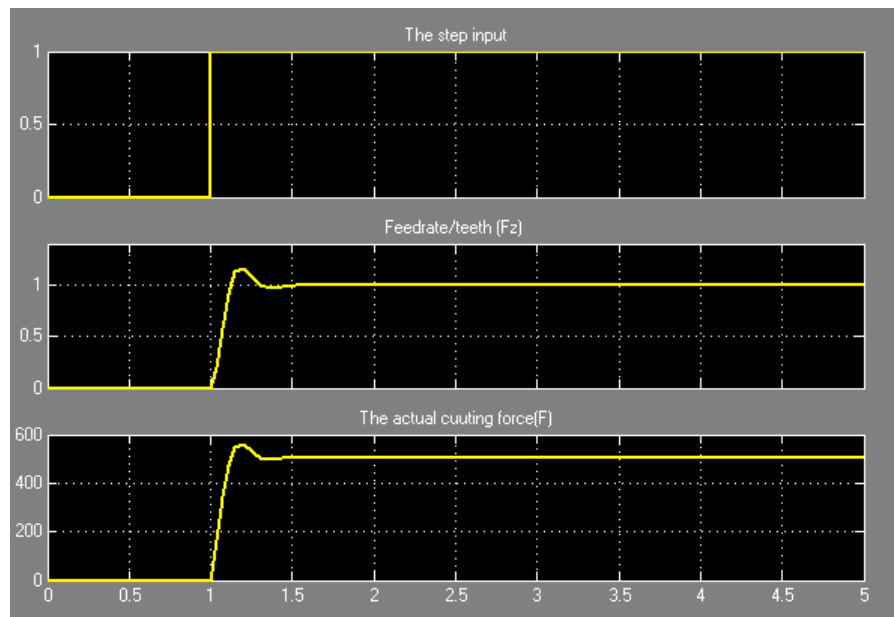

Figure 6. The Model Simulation

The output of this open loop model is the actual cutting force and according to the above Matlab three figures simulation the maximum value of the actual cutting force is similar with Simulink result. Now let's consider the model is active and correct.

\section{Adding Fuzzy Controller}

By using the same logic of fuzzy controller mentioned in [19 and20], then add the established milling machining system model. Figure 7 is a typical two-input and singleoutput schematic diagram based on the Fuzzy control logic. Controller's input linguistic variables are the difference between reference forces $F_{\text {ref }}$ and actual cutting forces $F$ and the change rate of the deviation, the output linguistic variable is per/tooth feed $f_{\mathrm{z}}, e$ is a deviation between an expectable value and the actual value, $e c$ is the change rate of deviation, $E$ and $C E$ are fuzzy controller input values, $K E$ and $\mathrm{K}_{C E}$ are quantitative factors and $K U$ is the proportional output factor. 


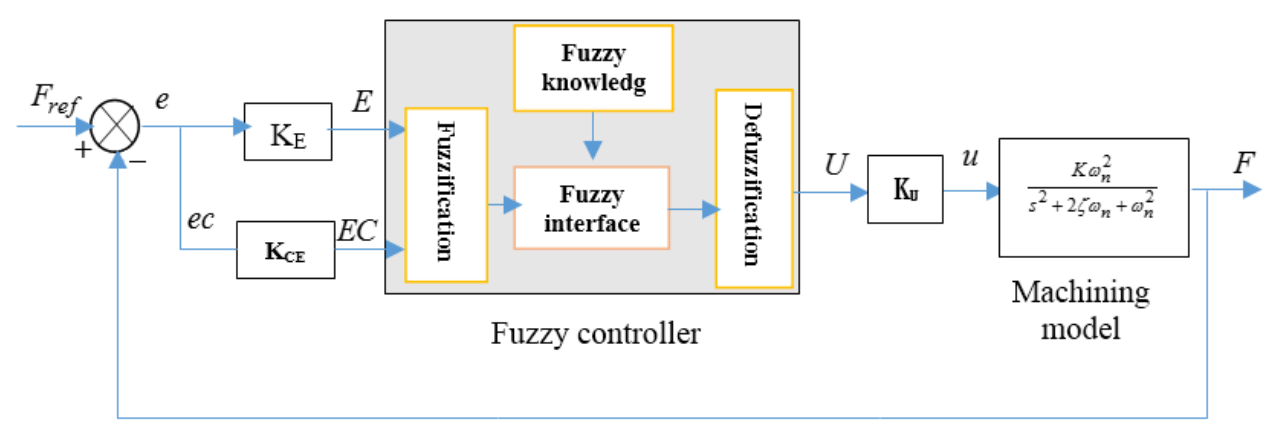

Figure 7. Milling Machining Control Schematic Based On Fuzzy Control

For, the deviation use the following equation:

$$
\begin{aligned}
& e(i)=F(i)-F_{r e f}(i) \\
& e(i)=[e(i)-e(i-1)] / \mathrm{dt}
\end{aligned}
$$

\section{Matlab Fuzzy Interface Method}

With the fuzzy interface engine, the rules combined the membership degree of fuzzy inputs determine the fuzzy outs put [6]. By using the Matlab fuzzy interface based on Mamdani -type implication.

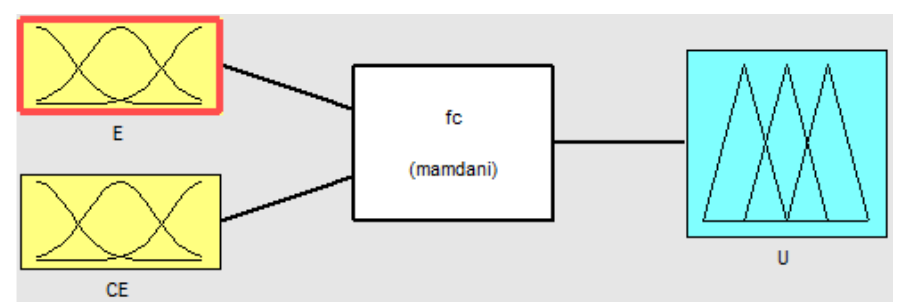

Figure 8. Fuzzy Interface Method Mandani Type Inputs and Output Variables

\subsection{Membership Function}

By using the method of triangle membership function, the input and output variables have been fuzzily transformed as shown in Figure 9. Variables are subordinated the following fuzzy subset are: [NL, NM, NS, Z, PS, PM, PL], which donate negative large (NL), negative medium (NM), negative small (NS), zero (Z), positive small (PS), positive medium (PM), positive large (PL). Let us consider the Error rang of the system is $[-6,6]$ with membership $\mu[0,1]$, so the discrete domain of $\mathrm{E}(i), \mathrm{EC}(i)$ and $\mathrm{U}(i)$ will be:[-6, -5 , $-4,-3,-2,-1,0,+1,+2,+3,+4,+5,+6]$.

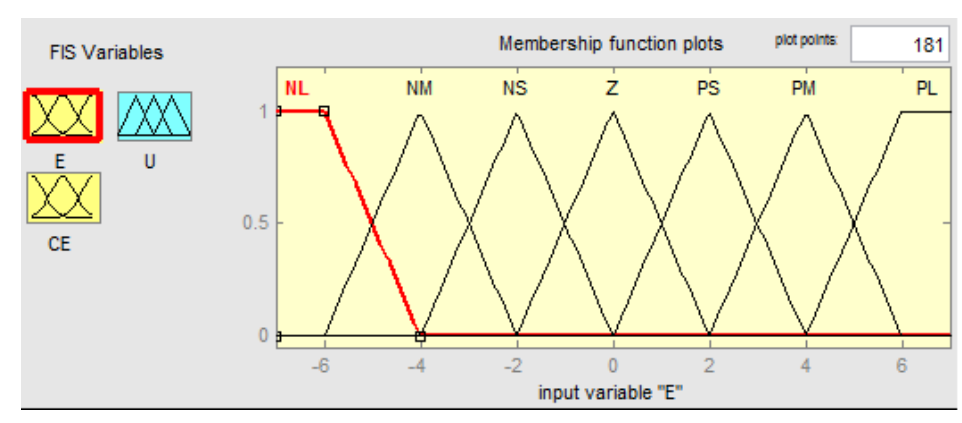

Figure 9. Subordinating Degree Function of Input and Output Variables 


\subsection{Control Rules}

According to this article, there are seven fuzzy sets associated with seven sets of fuzzy quantities for either power error or error change. Each combination of a power error fuzzy set and a power change fuzzy set requires a control action. The rules can be described as "if E and EC then U". The situation and corresponding control strategies are summarize as Table 2:

Table 2. Rules for Fuzzy Control

\begin{tabular}{|l|c|c|c|c|c|c|c|}
\hline \multicolumn{1}{|c|}{$\boldsymbol{E}_{\boldsymbol{E}}$} & NL & NM & NS & $\mathbf{Z}$ & PS & PM & PL \\
\hline NL & NL & NL & NL & NL & NM & NS & Z \\
\hline NM & NL & NL & NL & NM & NS & Z & PS \\
\hline NS & NL & NL & NM & NS & Z & PS & PM \\
\hline $\mathbf{Z}$ & NL & NM & NS & Z & PS & PM & PS \\
\hline PS & NM & NS & Z & PS & PM & PL & PS \\
\hline PM & NS & Z & PS & PM & PL & PL & PS \\
\hline PL & Z & PS & PM & PL & PL & PL & PS \\
\hline
\end{tabular}

After determine the fuzzy rules that expertise for the two dimensional control structure and the corresponding input fuzzy sets, we can make 49 fuzzy control rules as shown in figure 10 .

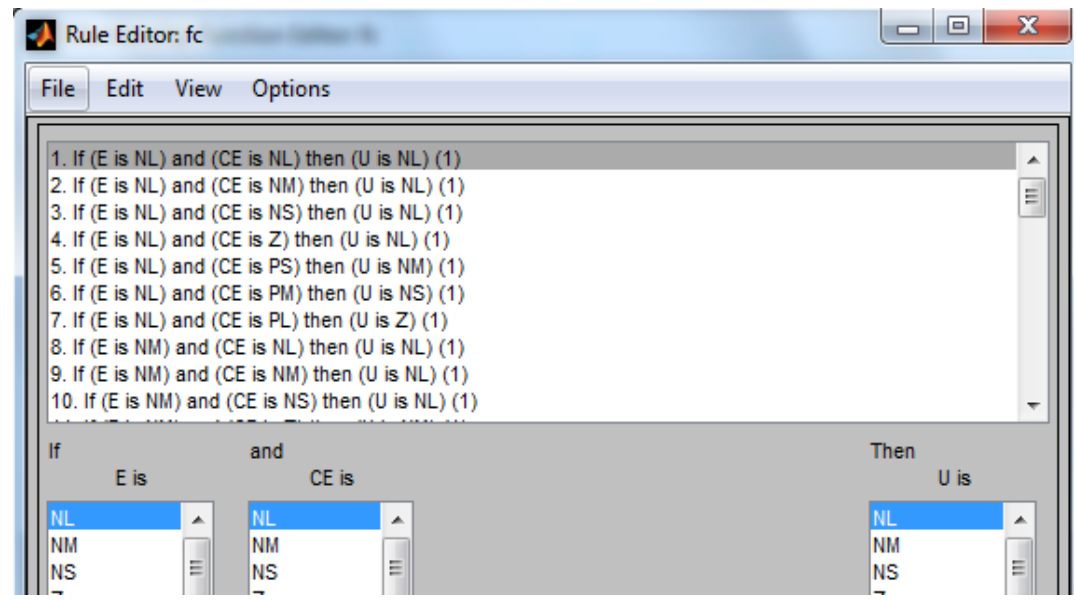

Figure 10. Control Rules Editor Window

\subsection{Defuzification}

Defuzzification is the conversion of a fuzzy quantity to a precise quantity, fuzzification that is the conversion of a precise quantity to a fuzzy quantity. It has been proposed by investigators in recent years, among popular for defuzzification methods: centroid, bisector, Mean of Maximum (mom), Largest of Maximum (lom) and Smallest of Maximum (som).To give more reliable results, Centroid of area defuzzification method is used calculate the script any additional blank lines between paragraphs.

\subsection{Fuzzy Interface System Verification}

Through the above four steps, fuzzy interface system is created. To simulate and view the results, rules viewer and surface viewer are used. Figure 11 shows the rule viewer, where sets of membership function for particular two input $E$ and $C E$, then one output $U$. 


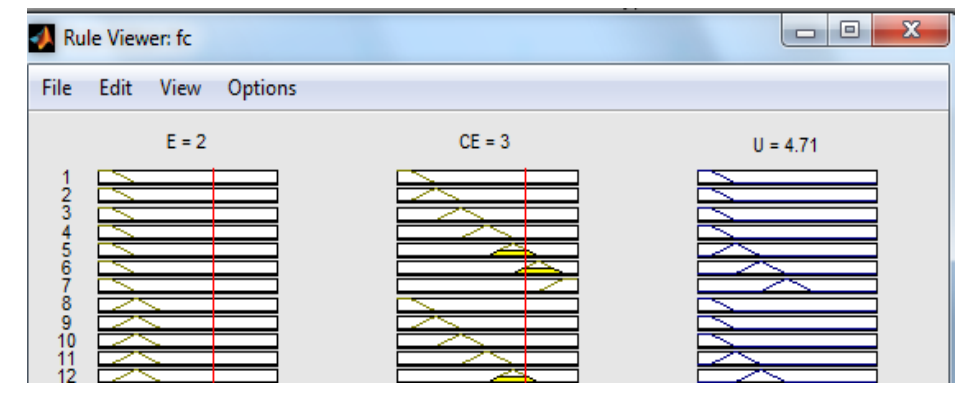

Figure 11. Rule Viewer Window

Another way to look at fuzzy logic system is surface viewer method figure 12 and 13, where control rules surface in 3D and 2 D. For Example:

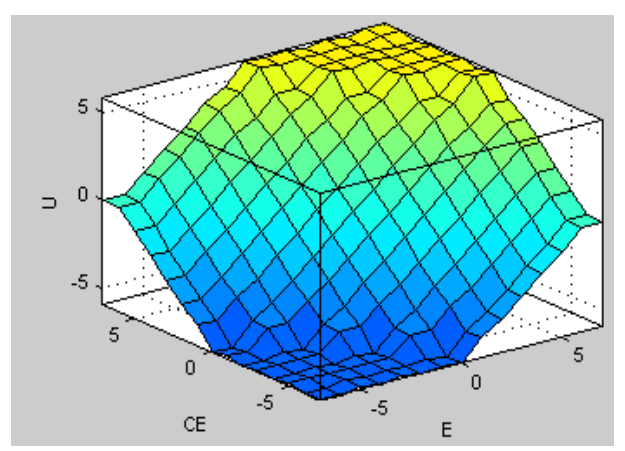

Figure 12. Control Rules Surface 3D
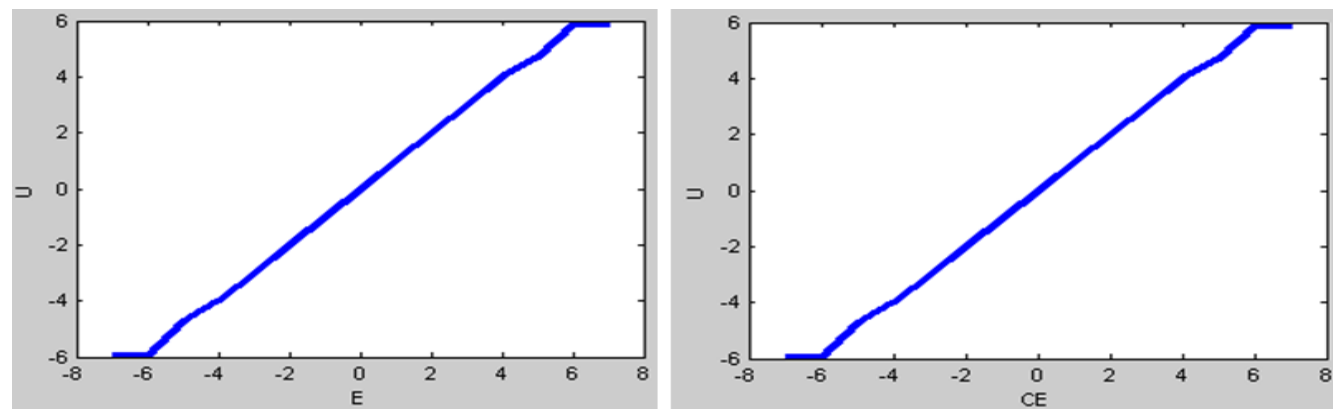

Figure 13. Control Rules Surface 2D

\section{The Final Simulink Model of the Whole System}

Assume a milling machining work piece with three value depth of cut 1, 2, 3 as shown in figure 15. The bottom of work piece considered as a reference of axial cutting depth, the top is 1 , the middle edge is 2 and the end is 3 .

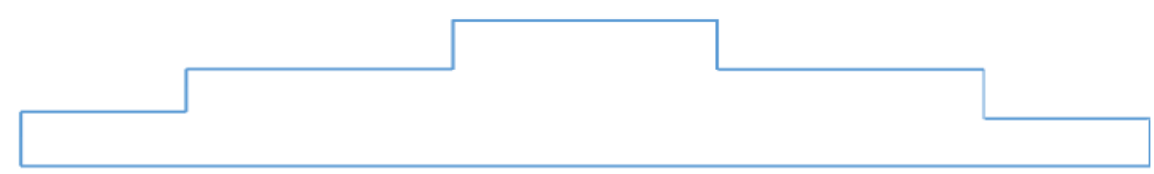

Figure 14. The Work Piece Axial Cutting Depth 
In order to generate the Fuzzy model transfer function to test the step response under various parameters, where the simulation parameters Table 1.Fuzzy interface method Mamdani type control system of Matlab/Simulink simulation model diagram is established, Figure 15.

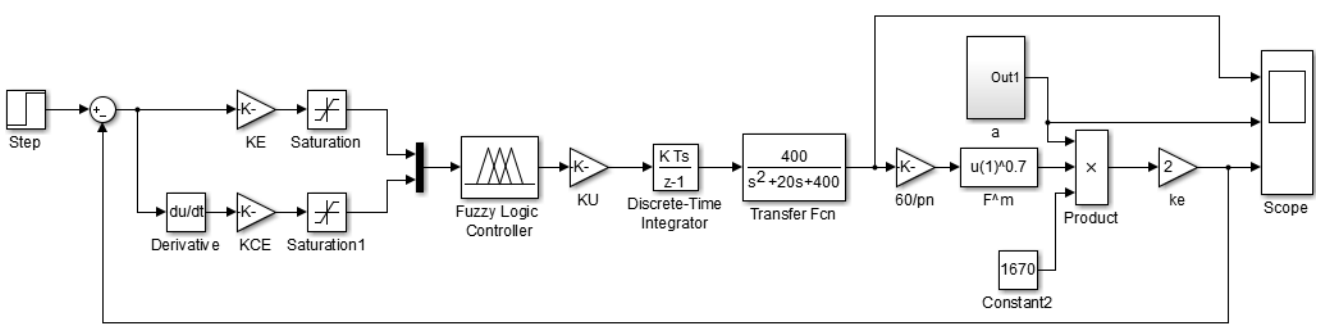
Figure 15. Simulation Block Diagram of Fuzzy Interface Control in
Matlab/Simulink

A Subsystem module established to achieve the change rule of cutting depth, as shown in eqeure 16, oblique wave output ramp is quantitatively outputted by the module Quantizer, the three cutting depth corresponding value is $1 \mathrm{~mm}, 2 \mathrm{~mm}$ and $3 \mathrm{~mm}$. When Multiport Switch port value is 1, the value of Constant 3 is outputted from the first input port to the output port. The rest is similar. Setting the Multiport Switch time, can be realized input different cutting depth at different times.

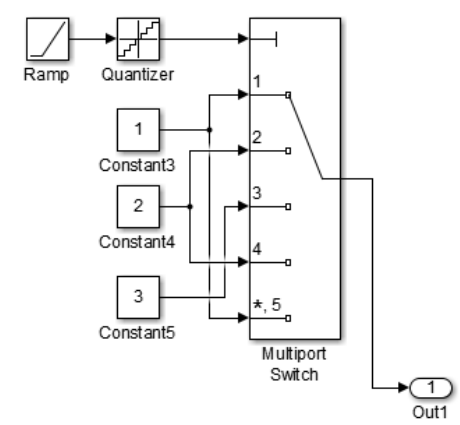

Figure 16. The Subsystem of Cutting Depth Step Change (a)

For the simulation set $K E$ gain to $0.1, K_{C E}$ to 0.01 , saturation limited (-6.6), $K u$ to 0.035 , the step block final value to $1000 \mathrm{~N}$ and the cutting process is active at $t=120 \mathrm{sec}$. 


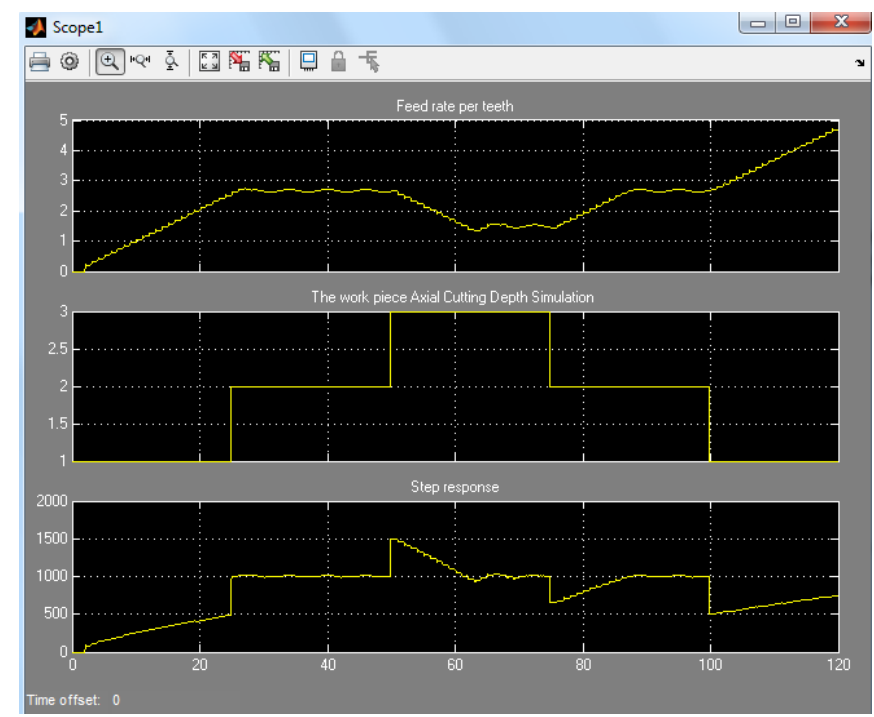

Figure 17. The Simulation Result

All though this method is more logic able, easy to determine the input and the output by using rule viewer, but the main problem of this work is the simulation. The simulation process is too slow and need to wait more time. Because of this problem I will consider this method is not the best and I need to find another method for more fast simulation results.

\section{Summary}

A milling control model has been developed by using cutting parameters and simulated in Matlab/Simulink as an open loop transfer function, to make the model is comparable Matlab simulation is done to find out the impact of the exponent of the specific $m$, damping ratio $\zeta$ and natural frequency $\omega_{n}$. Secondly the equation of milling process and servo system is establish, Simulink model is built and simulated the simulation result is comparable. Then, Matlab fuzzy interface based on Mamdani -type implication is established, to simulate and view the results, rules viewer and surface viewer are used. Next, Matlab/ Simulink model is establish according to logic of milling machining control Schematic Based On Fuzzy Control, the Matlab fuzzy interface based on Mamdani -type is added to the model through the Simulink fuzzy logic controller).by using the same parameters the model is simulated to find out the step response, finally, the advantage and dis advantage of this method are discussed.

\section{References}

[1] G. Chryssolouris, "Manufacturing Systems: Theory and Practice", 2nd Edition 606p, Springer-Verlag, New York, (2005).

[2] G., Chryssolouris, M.Domroese, , , An Experimental Study Of Strategies For Integrating Sensor Information In Machining" CIRP Annals, Volume 38, No.11989, pp. 425-428.

[3] G. Chryssolouris, M. Domroese and L. Zsoldos, "A Decision-Making Strategy For Machining Control”, CIRP Annals, vol. 39, no.1, (1990), pp. 501-504.

[4] G. Chryssolouris and M. Guillot, "A Comparison Of Statistical And AI Approaches To The Selection Of Process Parameters In Intelligent Machining", Journal Of Engineering For Industry, ASME, Volume 112, (1990), pp. 122-13.

[5] M. Joo Er and Y.L. Sun, "Hybrid Fuzzy Proportional Integral plus Conventional Derivative Control of Linear And Nonlinear Systems", IEEE Trans. On Industrial Electronics, vol.48, no.6, (2001), pp. 11091117.

[6] J. C. Wu and T. S. Liu, "A Sliding-Mode Approach to Fuzzy Control Design", Ieee Tran. On Control Systems Technology, vol.4, no.2, (1996), pp. 141-151. 
[7] H. X. Li and H. B. Gatland, “A New Methodology For Designing A Fuzzy Logic Controller”, Ieee Tran. On Sys. Man, And Cybernetics, vol.25, no.3, (1995), pp. 505-512.

[8] V.S. Sharma, S.K. Sharma and A.K. Sharma, "Cutting Tool Wear Estimation for Turning", J Intell Manuf., vol. 19, no. 1, (2008), pp. 99-108.

[9] E.H. Mamdani and S. Assilian, "an Experiment in Linguistic Synthesis with A Fuzzy Logic Controller", Int Jman Mach Stud., vol. 7, no. 1, (1975), pp. 1-13.

[10] P.J. King and E.H. Mamdani, "The Application Of Fuzzy Control Systems To Industrial Processes", Automatica, vol. 13,no. 3, (1977), pp. 235-242.

[11] H. Grote, Antonsson and K. Erik, "Springer Handbook of Mechanical Engineering", Isbn 978-3-54049131-6. 1576 S.

[12] H. Saglam, Y. Suleyman and F. Unsacar, "The Effect of Tool Geometry and Cutting Speed on Main Cutting Force and Tool Tip Temperature", Materials and Design 28, 2007. Dostupné Na www.Sciencedirect.Com.

[13] J. Kovalčík, "Cutting Force Effects Modelling And Spindle Load Prediction For Milling Technology".

[14] L. Elke, "Servo Control Systems 1: Dc Servo Mechanisms", White Paper, Control Systems Principles. Co. Uk.

[15] K. Saleh, "Modelling and Analysis of Chatter Mitigation Strategies in Milling", University Of Sheffield, (2013).

[16] J. Tlusty, Ed., "Manufacturing Processes and Equipment" Prentice Hall, Upper Saddle River, NJ, (2002)

[17] E.J. Armarego and C.J. Epp," an Investigation of Zero Helix Peripheral Up-Milling", International Journal of Machine Tool Design and Research, vol. 10, no. 2, (1970), pp. 273-\& vol. 38, no. 3, (1998), pp. 215-237.

[18] F. Oenigsberger and A.J.P. Sabberwal, "an Investigation into the Cutting Force Pulsations during Milling Operations", International Journal of Machine Tool Design and Research, vol. 1, (1961), pp. 1533.

[19] H. Huang, A. Li and L. Xu, "Fuzzy Control of Milling Process with Constraint of Spindle Power", In Intelligent Control and Automation, 2008. WCICA 2008. 7th World Congress On. IEEE, vol. 16, (2008).

[20] Y. Huang and J. Yuan, "High Speed Constant Force Milling Based On Fuzzy Controller And BP Neural Network", International Journal of Control and Automation, (2014), vol. 7, no. 5, pp. 143-152.

\section{Authors}

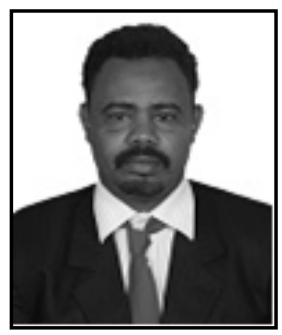

Bashir Osman, he is PHD student, Harbin Engineering University, College of Mechanical and Electrical Engineering, China. Work as a lecturer at Nile Valley University, Faculty of Engineering and Technology, Department of Mechanical Engineering, Sudan.

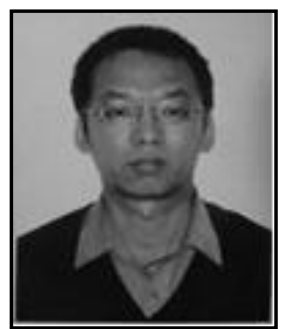

Haitao Zhu, he is a Professor, doctoral supervisor, College of Shipbuilding Engineering, Harbin Engineering University, China. Member of Expert group of enterprise informatization in Heilongjiang Province. Research on virtual manufacturing, CIMS and submersible. As project leader, has taken charge of a great variety of national/provincial scientific projects. 
International Journal of Control and Automation

Vol. 10, No. 2 (2017) 